\title{
MicroRNA-9 suppresses uveal melanoma cell migration and invasion through the NF-кB1 pathway
}

\author{
NANNAN LIU ${ }^{1,2}$, QINGMIN SUN ${ }^{3}$, JIE CHEN $^{4}$, JIAQI LI $^{1}$, YING ZENG ${ }^{1}$, \\ SULAN ZHAI ${ }^{1}$, PING LI ${ }^{1}$, BIN WANG ${ }^{1}$ and XUERONG WANG ${ }^{1}$ \\ ${ }^{1}$ Department of Pharmacology, Nanjing Medical University, Nanjing, Jiangsu Province; ${ }^{2}$ Department of \\ Pharmacology, Second Affiliated Hospital, Zhejiang University School of Medicine, Hangzhou, Zhejiang \\ Province; ${ }^{3}$ Department of Pharmacy, The Affiliated Wuxi Hospital for Maternal and Child Health Care \\ of Nanjing Medical University, Wuxi, Jiangsu Province; ${ }^{4}$ Department of Pharmacy, The Affiliated \\ Pingxiang Hospital, Southern Medical University, Pingxiang, Jiangxi Province, P.R. China
}

Received April 17, 2012; Accepted May 28, 2012

DOI: 10.3892/or.2012.1905

\begin{abstract}
The aggressive course of uveal melanoma is believed to reflect its unusually invasive and metastatic nature, which is associated with the nuclear factor kappaB $(\mathrm{NF}-\kappa \mathrm{B})$ pathway. MicroRNAs (miRNAs) have been implicated in the regulation of various biological and pathological processes in cancer, however, the special role of miR-9 in uveal melanoma metastasis is largely unknown. In the present study, we showed that miR-9 is significantly reduced in highly invasive uveal melanoma cell lines, and suppressed migration and invasion of highly invasive cells. Furthermore, miR-9 negatively modulated NF- $\kappa$ B1 expression by direct targeting at its 3'-UTRs. Additionally, downstream targets of NF- $\mathrm{BB} 1$, such as MMP-2, MMP-9 and VEGFA, were regulated by miR-9 in the same pattern as NF- $\kappa \mathrm{B} 1$. Therefore, miR-9 suppresses uveal melanoma cell migration and invasion partly through downregulation of the NF- $\kappa \mathrm{B} 1$ signaling pathway.
\end{abstract}

\section{Introduction}

Uveal melanoma is the most common primary intraocular malignant tumor in adults with a high mortality of $\sim 50 \%$ (1). Early metastasis accounts for the high death rate of uveal melanoma (2). Unfortunately, it is evidenced that many patients may have subclinical metastasis at the time of diagnosis (1). Despite the advances in surgery, radiotherapy and chemotherapy, the 5-year relative survival rate has not improved from 1973 to 2008 (3). Metastasis of uveal melanoma is a complex and multistep process, involving increased migratory and invasive potential of tumor cells. Currently, the molecular mechanisms of its aggressiveness are still not elucidated (4). Therefore, identifying the

Correspondence to: Dr Xuerong Wang, Department of Pharmacology, Nanjing Medical University, 140 Hanzhong Road, Nanjing 210029, Jiangsu Province, P.R. China

E-mail:wangxrwn@hotmail.com

Key words: miR-9, migration, invasion, NF-кB1, uveal melanoma crucial signals that promote invasive and metastatic potential of uveal melanoma will contribute to provide biomarkers for early prognosis and targets for treatment.

MicroRNAs (miRNAs) are 22 nt non-coding RNAs that negatively regulate gene expression at the post-transcriptional level via direct binding with the 3 ' untranslated regions (UTRs) of target mRNAs. Many miRNAs have been implicated to play important roles in tumor metastasis, such as miR-9, miR-31, miR-125a, miR-373 (5). Accumulated evidence has shown the involvement of miR-9 in tumor cell proliferation and tumor progression (6-8). More attention was paid to miR-9 mediatedtumor cell proliferation; however, the current knowledge about miR-9 in tumor metastasis is still preliminary. MiR-9 has been shown to promote tumor metastasis in breast cancer and colorectal cancer $(9,10)$. Whereas, a recent study showed that miR-9 suppressed melanoma progression (11). Currently, the role of miR-9 in metastasis of uveal melanoma and the possible mechanism have not been reported.

$\mathrm{NF}-\kappa \mathrm{B}$ (nuclear factor kappaB) is a transcription factor that plays important roles in cell proliferation, apoptosis, differentiation, as well as in tumor angiogenesis and metastasis (12). The mammalian NF- $\mathrm{B}$ family is composed of five members,

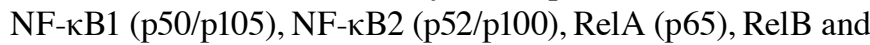
$c-$ Rel. NF- $\kappa \mathrm{B}$ regulates gene transcription activity through forming a complex containing hetero- or homo-dimers of the five subunits and other adaptor proteins and binding to the promoter of the responsive gene (13). MMP-2 (matrix metalloproteinase), MMP-9, and VEGFA (vascular endothelial growth factor A) are some responsive genes of NF- $\kappa$ B1 involved in tumor invasion and metastatasis, and their upregulation has been suggested to be correlated with metastasis of uveal melanoma $(14,15)$. Bioinformatic analysis reveals a conserved target site for miR-9 in the NF-кB1-3'-UTR at nucleotides 3405-3412. Moreover, NF- $\kappa \mathrm{B} 1$ has been shown to be a direct target gene of miR-9 in certain types of cancer $(7,11)$. However, for its role in uveal melanoma metastasis has not been reported.

In this study, we identified an inverse correlation between miR-9 expression and uveal melanoma cell invasive potential. We further addressed miR-9-mediated tumor cell migration and invasion, and identified NF- $\mathrm{NB} 1$ as a direct target of miR-9. 
Additionally, we showed MMP-2, MMP-9, and VEGFA, the downstream signals of $\mathrm{NF}-\kappa \mathrm{B} 1$, were regulated by miR-9 simultaneously.

\section{Materials and methods}

Cell culture and transfection. Paired human uveal melanoma cells with highly invasive potential (MUM-2B and C918) and the relatively poorly invasive potential (MUM-2C and OCM-1A) were kindly provided by Professor Elisabeth A. Seftor (Children's Memorial Research Center, Chicago, IL). The highly invasive MUM-2B cells were transfected with miR-9 mimic (miR-9) or the negative control mimic (miRcon) (Dharmacon, Lafayette, CO) using Lipofectamine 2000 (Invitrogen) following the manufacturer's protocol. The poorly invasive MUM-2C cells were transfected with miR-9 inhibitor (anti-miR-9) or the negative control inhibitor (anti-miR-con) as above.

Quantitative real-time polymerase chain reaction. Total RNA was extracted from cells using Trizol reagent (Invitrogen). TaqMan microRNA assays (Applied Biosystems Inc., Foster City, CA) were used to quantify the relative expression of miR-9. Small nuclear RNA, U6B (Applied Biosystems Inc.), was treated as normalization control. NF- $\kappa \mathrm{B} 1, \mathrm{MMP}-2$, MMP-9, VEGFA, and GAPDH (control) mRNA levels were assessed by SYBR Green quantitative PCR. Reactions were conducted according to the manufacturer's instructions using Power SYBR Green PCR Master Mix (Applied Biosystems Inc.). Forward (F) and reverse (R) primers were used as follows: NF- $\mathrm{BB} 1, \mathrm{~F}$ : 5'-ACAG CAGATGGCCCATACCT-3' and R: 5'-CATACATAACGGA AACGAAATCCTCT-3'; MMP-2, F: 5'-TCCCATTTTGATGA CGATGA-3' and R: 5'-CCGTACTTGCCATCCTTCTC-3'; MMP-9, F: 5'-CATCGTCATCCAGTTTGGTG-3' and R: 5'-TCGAAGATGAAGGGGAAGTG-3' ; VEGFA, F: 5'-CCTT GCTGCTCTACCTCCAC-3' and R: 5'-ATGATTCTGCCC TCCTCCTT-3'; GAPDH, F: 5'-TGTTCGACAGTCAGC CGC-3', and R: 5'-GGTGTCTGAGCGATGTGGC-3'. All realtime amplifications were measured in triplicate and performed with the ABI PRISM 7300 sequence detection system. The fold-change of miR-9, NF-кB1, MMP-2, MMP-9, and VEGFA mRNA was calculated using the $2^{-\Delta \Delta C T}$ method.

Cell proliferation assay. Cell proliferative activity was determined by the MTT (3-[4,5-dimethyl-thiazol-2-yl]-2,5-diphenyltetrazolium bromide) assay, according to standard methods (4). Absorbance was measured at $490 \mathrm{~nm}$ and detected using $\mu$ Quant Universal Microplate Spectrophotometer (BioTek Instruments, Inc.).

Invasion assay. The invasion assay was performed using cultrex-24-well membrane invasion chambers $(8 \mu \mathrm{m}$ pore size, Millipore). Briefly, $40 \mu \mathrm{l}$ of coating solution (BD matrigel diluted with medium at the rate of 1:3, BD Biosciences, San Jose, CA) was placed in each well of the top invasion chamber, and the cells were starved in serum-free medium. Post-transfection cells $(24 \mathrm{~h})$ were harvested, resuspended in serum-free medium and seeded into the top chamber at $1 \times 10^{4}$ cell/well. Complete medium $(600 \mu \mathrm{l})$ with $12 \%$ FBS was added to the bottom wells of the chambers. The chambers were incubated at $37^{\circ} \mathrm{C}$ in an incubator containing 5\% $\mathrm{CO}_{2}$. After $24 \mathrm{~h}$, the non-invading cells were removed from the top chamber. The invading cells were fixed with methanol and stained by $0.05 \%$ crystal violet solution. The number of invasive cells on the lower surface of the membrane was counted under a microscope. The mean of triplicate assays for each experimental condition is reported.

Migration assay. Cell migration was also measured with cultrex24-well membrane invasion chambers, without coating solution. Briefly, post-transfected cells were harvested and transferred with $5 \times 10^{3}$ cells to milicell inserts. After culture for $16 \mathrm{~h}$, migrated cells were fixed, stained and counted as above.

MiR-9 target prediction. Computer-based programs were used to predict potential miR-9 targets. Using 'hsa-miR-9' as a search term, we queried PicTar (http://pictar.mdc-berlin.de/), TargetScan (http://targetscan.org/) and miRBase targets (http:// mirbase.org/). A gene was considered to be a putative target of miR-9 only if it was predicted by three programs.

Plasmid construction. Plasmid pcDNA3.1-EGFP was derived from pCDNA3.1(+) (Invitrogen) by inserting the coding EGFP fragment at HindIII and BamHI sites. The EGFP fragment was amplified from pEGFP-N1 (Clontech, CA, USA) with primers of EGFP forward, 5'-GCAGCCAAGCTTGCCACCA TGTGTAGCAAGGGC-3', and EGFP reverse, 5'-CGCGGAT CCTTTACTTGTACAGCTCGTCC-3'. The 3'-untranslated mRNA sequences of NF- $\kappa$ B1 containing the predicted miR-9 binding site (nt 3405-3412) were synthesized by Invitrogen with BamHI and EcoRI enzyme digest sites at 5' end and $3^{\prime}$ end, respectively. Similar fragments with specifically mutated miR-9 targeting region were also synthesized. The oligonucleotides were cloned into pcDNA/EGFP at the BamHI and EcoRI sites, and named as pcDNA-EGFP-NF- $\kappa \mathrm{B} 1-\mathrm{Wt}$ (Wt-3'-UTR) and pcDNA-EGFP-NF-кB1-Mut (Mut-3'-UTR) respectively. All constructs were verified by DNA sequencing.

Fluorescent report assay. MUM-2B cells were seeded in 24-well plates and were transfected with miR-9 mimic or the negative control mimic for $24 \mathrm{~h}$, and then transfected with wildtype or mutant reporter vectors. The cells were washed twice with cold PBS, then lyzed with RIPA lysis buffer (150 mmol/l $\mathrm{NaCl}, 50 \mathrm{mmol} / \mathrm{l}$ Tris-HCl, $\mathrm{pH} 7.4,1 \%$ Triton $\mathrm{X}-100,0.1 \%$ SDS). Afterward protein was harvested, transferred to 96-well Black Cliniplate (Corning) and then the fluorescent intensity was measured on a varioskan fluorescence spectrometer (Thermo). The RFP expression vector, pDsRed-N1 (Clontech), was co-transfected and used for normalizing the transfection efficiency.

Western blot analysis. Cells were harvested at the end of treatment. Protein concentration was confirmed by the Bradford assay. Protein was separated by $10 \%$ SDS-PAGE and then transferred to PVDF membrane using standard procedures. The membrane was incubated with the primary antibody for NF- $\kappa$ B1 (Sigma, St. Louis, MO) or $\beta$-actin (Boster, Wuhan, China), and then washed, incubated with HRP-conjugated secondary antibody. Intensity of the bands was visualized by an enhanced chemiluminescence (ECL, Amersham Pharmacia Biotech) system and exposed. 


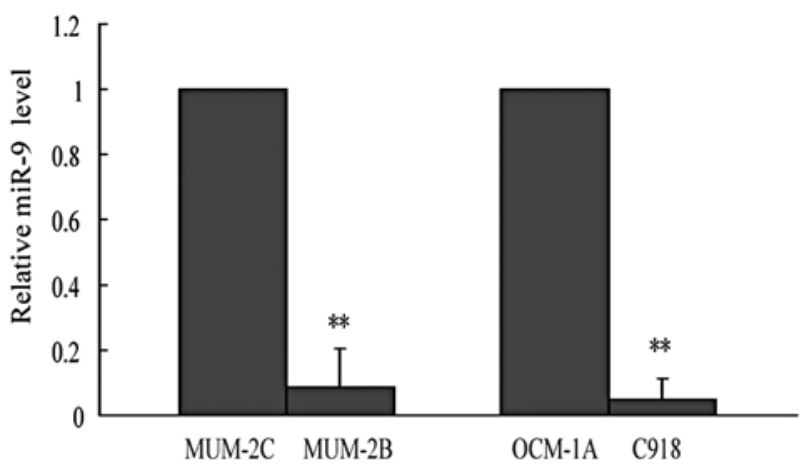

Figure 1. Identification of miR-9 expression in uveal melanoma cell lines. Level of miR-9 expression was investigated by real-time RT-PCR and normalized to that of snRNA U6B (RNU6B). The bars represent relative fold changes between two paired poorly and highly invasive uveal melanoma cell lines (MUM-2C vs MUM-2B, OCM-1A vs C918). Mean $\pm \mathrm{SD}$ of triplicate measurements. ${ }^{*} \mathrm{P}<0.05$; ${ }^{* * *} \mathrm{P}<0.01$.

Statistical analysis. The data are represented as the mean \pm SD. The difference between the groups was determined by non-parametric test. Differences with $\mathrm{P}<0.05$ were considered statistically significant. All the analyses were carried out with the SPSS 9.0 (SPSS Inc., Chicago, IL, USA).

\section{Results}

MiR-9 expression negatively correlates with the invasive potential of uveal melanoma cell lines. To test the possibility that miR-9 was involved in tumor cell invasion, two paired highly/poorly invasive human uveal melanoma cell lines were applied (MUM-2B vs MUM-2C, C918 vs OCM-1A), which had been successfully used in several studies investigating tumor metastasis $(1,16)$. We first detected miR-9 expression levels in these cell lines, and our data showed that miR-9 expression was dramatically reduced by $91 \%$ in highly invasive uveal melanoma MUM-2B cells compared with the corresponding poorly invasive MUM-2C cells. Another paired highly/poorly invasive cell lines confirmed the negative correlation between miR-9 and invasive capability, that miR-9 expression was severely repressed by $95 \%$ in highly invasive C918 cells in comparison with poorly invasive OCM-1A cells (Fig. 1). These data indicated that miR-9 might be involved in tumor metastasis and function as a tumor metastasis suppressor.

Ectopic expression of miR-9 leads to the reduction of cell migration and invasion. To determine the function of miR-9 on cell migration and invasion, MUM-2B cells were transfected with miR-9 mimic or negative mimic, and then evaluated in transwell assays with or without matrigel coating solution in the upper side of the well membrane. As shown in Fig. 2A, in the migration assay, cell numbers migrating to the lower side of the membrane after miR-9 mimic transfection decreased by $24 \%(\mathrm{P}<0.01)$ as compared to negative control mimic transfection. Re-expression of miR-9, cell numbers invading to the bottom side of the matrigel coating membrane decreased by $35 \%(\mathrm{P}<0.01)$ (Fig. 2B). These results suggest that ectopic expression of miR-9 repressed migratory and invasive potential of highly aggressive uveal melanoma cells. In addition, we
$\mathbf{A}$

\section{$\underline{\text { Migration assay }}$}
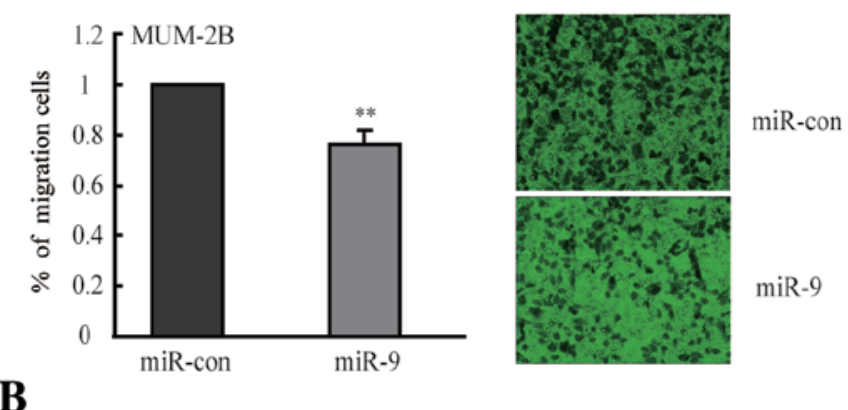

B

\section{$\underline{\text { Invasion assay }}$}
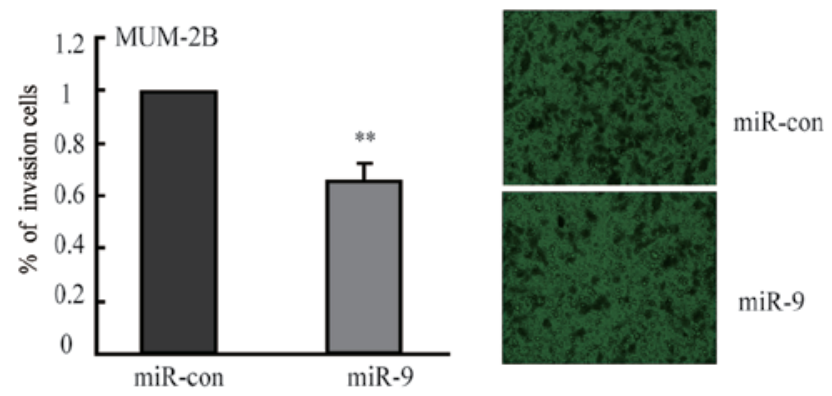

$\mathbf{C}$

$\underline{\text { MTT cell proliferation assay }}$

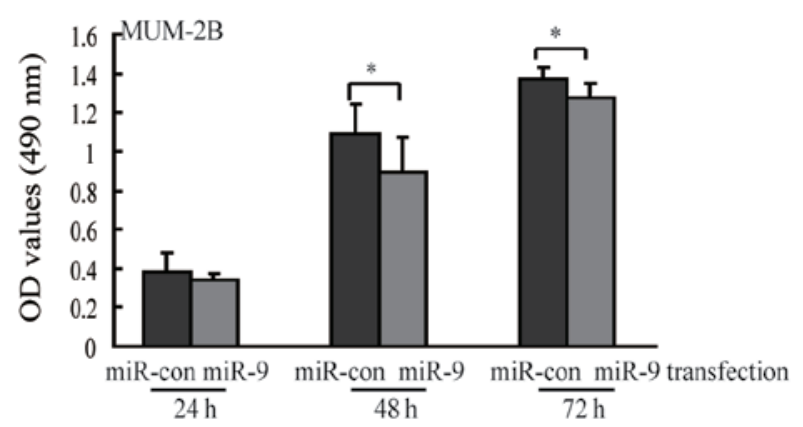

Figure 2. miR-9 suppresses uveal melanoma cell migration and invasion. (A) Migratory and (B) invasive capacity changes after MUM-2B cells transfected with miR-9 mimic (miR-9) or microRNA negative control mimic (miR-con) for $40 \mathrm{~h}$ (A) and $48 \mathrm{~h}$ (B) respectively. Average numbers of migrated cells were counted from three independent experiments and presented as mean \pm SD. Representative field of migrated and invasive cells on the membrane. In images, the green reflects background which could be seen with pores, whereas the black are cells that migrated or invaded. (C) Effect of miR-9 on cell proliferation for transfection after 24,48 and $72 \mathrm{~h}$.

observed inhibition of cell proliferation after introduction of miR-9 for 48 and $72 \mathrm{~h}$, but the effects were relatively minor (Fig. 2C).

$N F-\kappa B 1$ is a critical downstream target of miR-9. In order to explore the molecular mechanism by which miR-9 functions as a tumor suppressor, we chose three algorithm programs to predict the putative target genes. Among these genes, NF-кB1 was of particular interest, since it is a well-known oncogene involved in cancer development and upregulated in a variety of solid tumors $(13,17)$. In the present study, we found that NF- $\kappa B 1$ mRNA and protein expression were enhanced in highly invasive cell lines (MUM-2B, C918) compared with 


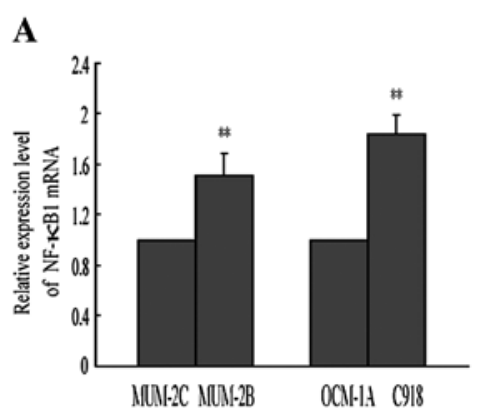

C

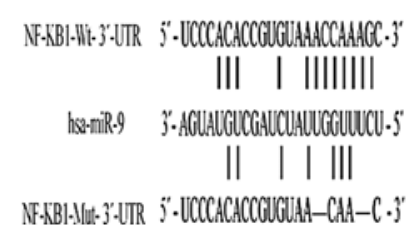

B

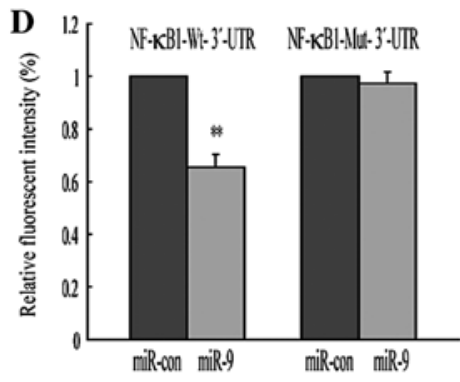

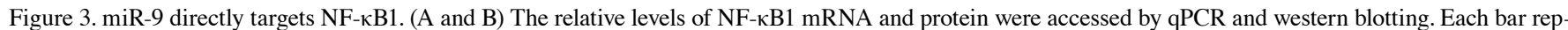
resents the relative fold change in two paired highly-poorly invasive cell lines. (C) Alignment of miR-9 with NF- $\mathrm{kB} 1$ at the 3'-UTRs. Along with a mutated NF- $\mathrm{BB} 1$ 3'-UTRs in which contains 4-base deletion at the miR-9-target region abolishing its binding. (D) Fluorescence reporter assay, Fluorescence reporters of EGFPNF-kB1 3'-UTR or EGFP-NF-кB1 mutant 3'-UTR in MUM-2B cells transfected with miR-9 mimic (miR-9) or the microRNA negative control mimic (miR-con).

$\mathbf{A}$
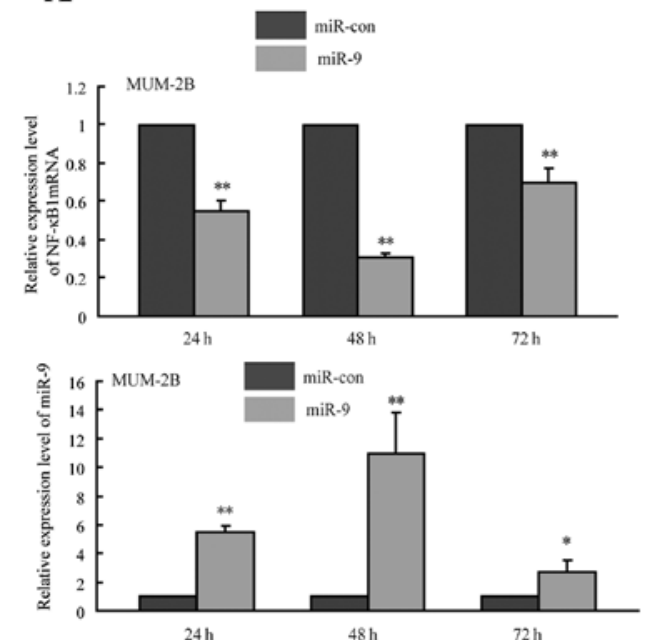

B
C
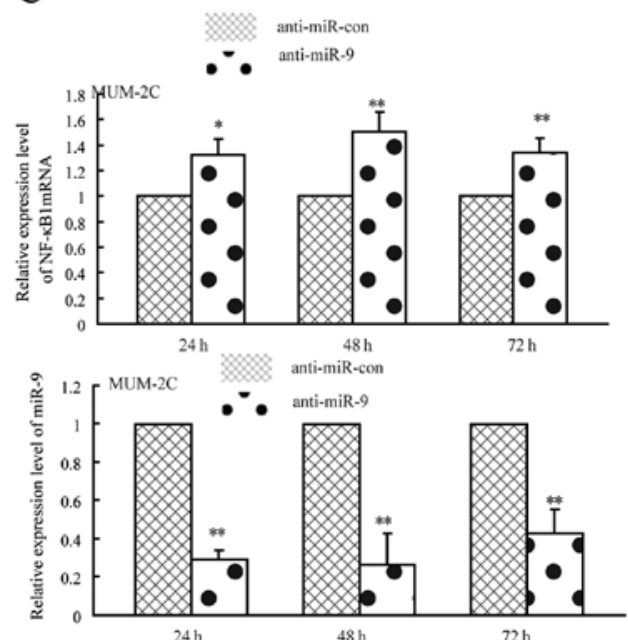

$48 \mathrm{~h}$
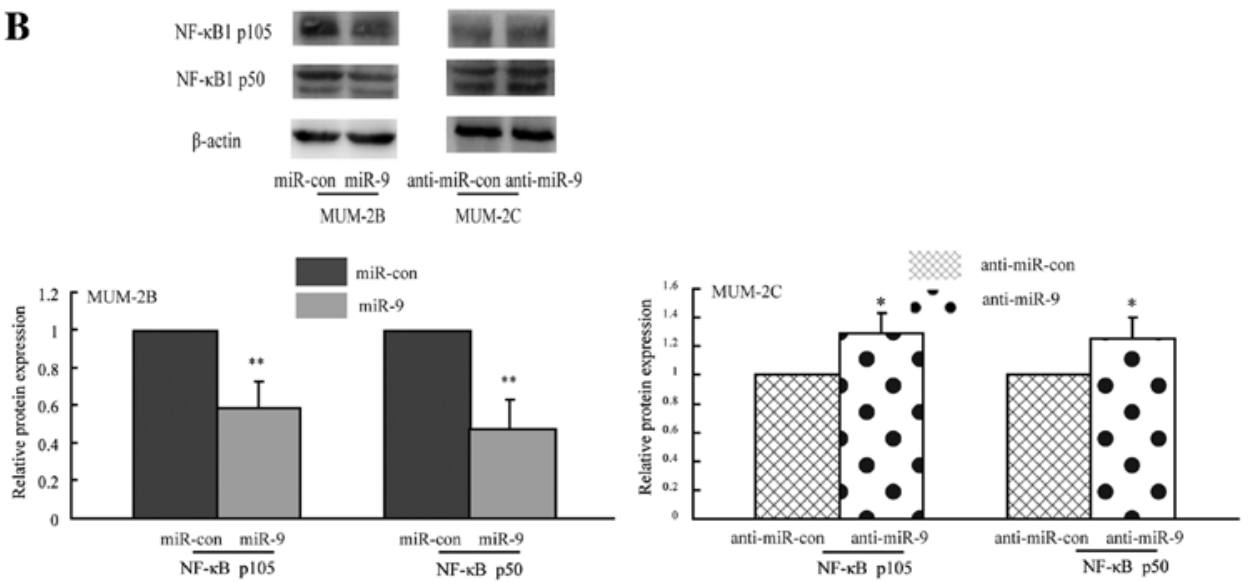

Figure 4. miR-9 negatively regulates NF- $\kappa$ B1 mRNA and protein expression. (A) The regulation of miR-9 and NF- $\mathrm{B} 1 \mathrm{mRNA}$ after the gain of miR-9 function in MUM-2B cells for 24, 48 and $72 \mathrm{~h}$. (B) miR-9 negatively regulated NF- $\kappa$ B1 protein levels after transfection miR-9 mimic in MUM-2B cells or transfection miR-9 inhibitor in MUM-2C cells for $48 \mathrm{~h}$. (C) Transfection with miR-9 inhibitor (anti-miR-9) or microRNA negative control inhibitor (anti-miR-con) influenced miR-9 and NF- $\kappa$ B1 mRNA expression in MUM-2C cells. 
the corresponding poorly invasive cell lines (MUM-2C, OCM-1A) (Fig. 3A and B), consistent with previous studies. As shown in Fig. 3C, there is a conserved target site for miR-9 in the NF- $\mathrm{KB} 1-3$ '-UTR at nucleotides 3405-3412. Combination of Figs. 1 and 3 show increased expression of NF- $\kappa \mathrm{B} 1$ was parallel with reduced abundance of miR-9, indicating that NF- $\mathrm{KB} 1$ may be a target of miR-9 in the regulation of tumor cell invasion. To identify NF- $\mathrm{kB} 1$ as a direct target of miR-9 in uveal melanoma cells, we constructed two enhanced green fluorescence protein (EGFP) reporter vectors containing the 3'-UTRs of NF- $\kappa$ B1. Wt-3'-UTR vector harbored the target sequence (AACCAAAG) of miR-9 seed region in NF- $\kappa$ B1. The parallel vector, Mut-3'-UTR, contained the specific mutation at the miR-9-targeted region to abolish the miR-9 binding (Fig. 3C). Fig. 3D shows that transient transfection of MUM-2B cells with miR-9 mimic and Wt- 3'-UTR report vector led to a significant decrease of fluorescence intensity compared with the control. However, the fluorescence intensity was unaffected when Mut-3'-UTR reporter vector and miR-9 mimic were cotransfected. These results suggest that miR-9 could directly bind to NF- $\mathrm{kB} 1$ and may regulate its expression in post-transcriptional levels.

MiR-9 negatively regulates $N F-\kappa B 1 \mathrm{mRNA}$ and protein expression. To determine whether miR-9 regulated endogenous NF- $\kappa \mathrm{B} 1$ expression in uveal melanoma cells, we performed gain-loss of function assays. Briefly, highly invasive MUM-2B cells with low miR-9 expression were transfected with miR-9 mimic to enhance the miR-9 function; meanwhile, poorly invasive MUM-2C cells carrying high miR-9 expression were transfected with miR-9 inhibitor to block the miR-9 function, then the effects of miR-9 on NF- $\mathrm{kB} 1 \mathrm{mRNA}$ and protein expression were measured by quantitative PCR and western blotting. As shown in Fig. 4A, NF- $\mathrm{kB} 1 \mathrm{mRNA}$ level was reduced by 45,69 and $31 \%$ after MUM-2B cells transfection of miR-9 mimic for 24, 48 and $72 \mathrm{~h}$, respectively, indicating that miR-9 regulates endogenous NF- $\mathrm{kB} 1 \mathrm{mRNA}$ levels partly through the mechanism of mRNA degradation. The NF- $\kappa \mathrm{B} 1$ gene encodes two functional proteins p105 and p50. Overexpression of miR-9 in MUM-2B cells led to reduction of NF- $\mathrm{KB}$ p105 and $\mathrm{p} 50$ proteins, respectively, by 42 and 52\% compared with the control groups, suggesting that miR-9 regulated NF- $\mathrm{KB} 1$ partly through translational repression and/or mRNA degradation (Fig. 4B). In contrast, blocking the expression of miR-9 in MUM-2C cells led to 32,50 and $34 \%$ increase of NF- $\mathrm{kB} 1 \mathrm{mRNA}$ for $24 \mathrm{~h}, 48$ and

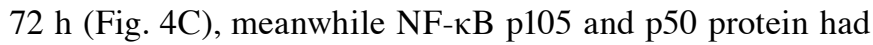
a 29 and 25\% increase after loss of miR-9 expression (Fig. 4B), supporting the negative regulatory function of miR-9 on NF- $\mathrm{KB} 1$ expression. These data showed that miR-9 restoration reduced NF- $\mathrm{KB} 1$ expression both in mRNA and protein levels in MUM-2B cells; silencing miR-9 expression increased NF- $\kappa$ B1 mRNA and protein amounts in MUM-2C cells. These findings suggest that miR-9 negatively regulates NF- $\kappa$ B1 expression at post-transcriptional level in highlypoorly invasive uveal melanoma cells.

MiR-9 indirectly regulates MMP-2, MMP-9, and VEGFA expression. It has been reported that activated NF- $\mathrm{KB}$ transcription factors resulted in increased expression of MMP-2,
A
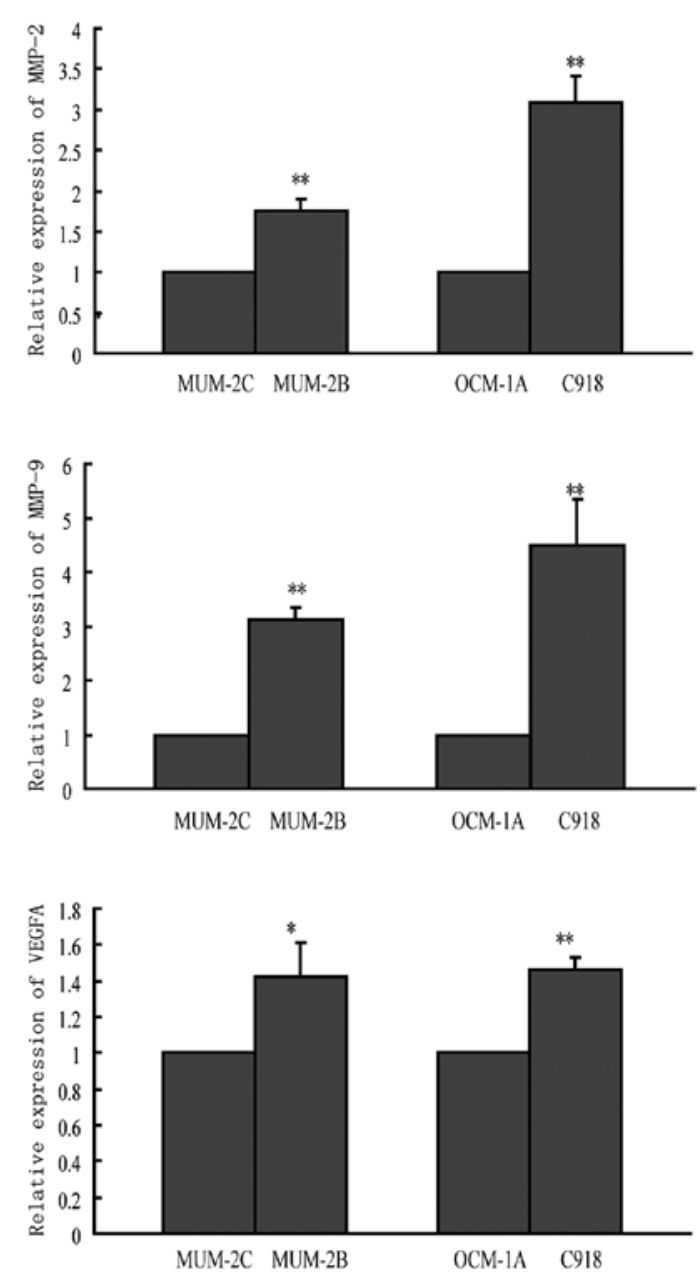

Figure 5. miR-9 indirectly regulates MMP-2, MMP-9 and VEGFA mRNA expression. (A) MMP-2, MMP-9, and VEGFA mRNA levels in two paired uveal melanoma cell lines.

MMP-9 and VEGFA, and contributed to tumor angiogenesis and metastasis $(18,19)$. Thus, we suspect that miR-9-regulated NF- $\kappa$ B1 expression may suppress invasive capability of uveal melanoma cells partly through MMP-2, MMP-9, and VEGFA. We first detected MMP-2, MMP-9, and VEGFA mRNA expression in two paired highly-poorly invasive cell lines. Fig. 5A showed increased expression of all three molecules in highly invasive cell lines (MUM-2B, C918) compared to the corresponding poorly invasive cell lines (MUM-2C, OCM-1A), similar to NF- $\mathrm{kB} 1$ expression. Then, we detected the effect of miR-9 on MMP-2, MMP-9, and VEGFA mRNA expression. As expected, miR-9 overexpression decreased mRNA expression levels of all three molecules (Fig. 5B). In contrast, anti-miR-9 increased their mRNA levels (Fig. 5C). The alteration was similar to the changes of NF- $\mathrm{kB} 1$ expression. Since in silico analysis did not show any miR-9 binding sites in the 3'-UTRs of MMP-2, MMP-9, and VEGFA, the suppression is possibly an indirect effect through NF- $\kappa B 1$. Therefore, reduction of MMP-2, MMP-9, and VEGFA expression through targeting NF- $\mathrm{kB} 1$ is likely to contribute to the miR-9-mediated suppression of cell invasion. 
B
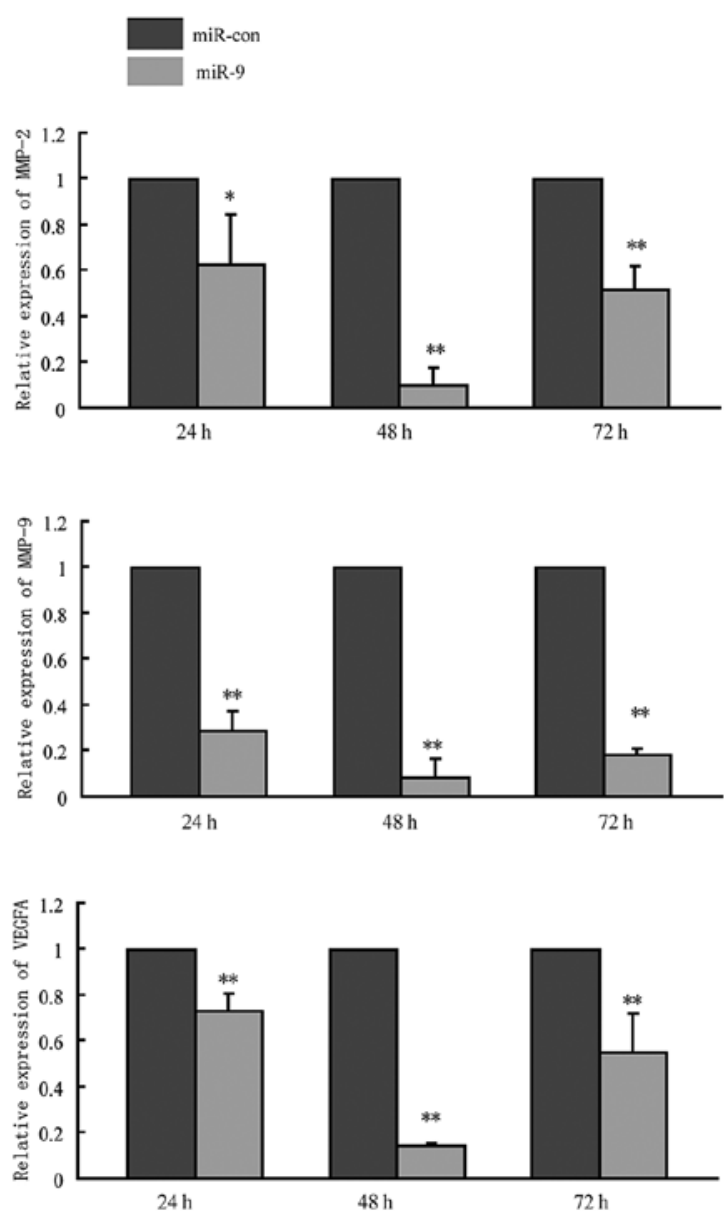

C
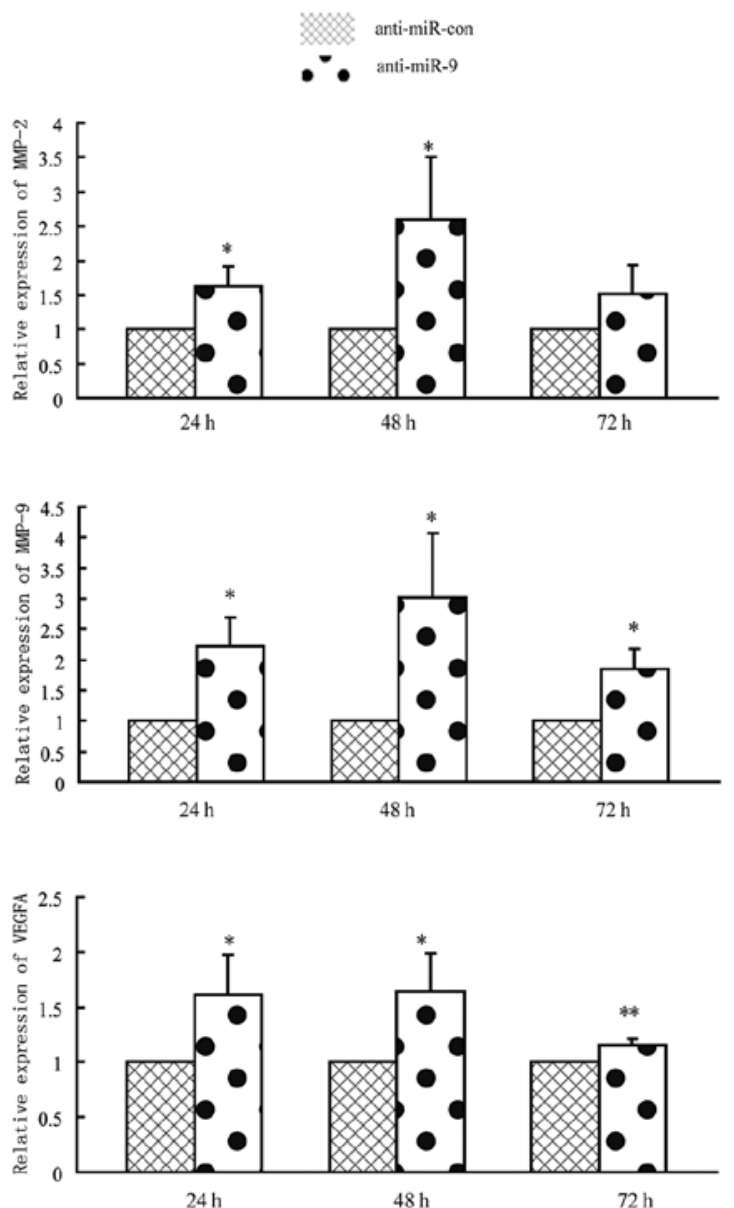

Figure 5. Continued. miR-9 indirectly regulates MMP-2, MMP-9 and VEGFA mRNA expression. (A) MMP-2, MMP-9, and VEGFA mRNA levels in two paired uveal melanoma cell lines. MMP-2, MMP-9 and VEGFA mRNA expression levels at 24, 48 and $72 \mathrm{~h}$ after ectopic expression of miR-9 (B) or reduction of miR-9 expression (C) in MUM-2B cells or MUM-2C cells. The relative expression of MMP-2, MMP-9 and VEGFA mRNA was normalized to that of GAPDH control.

\section{Discussion}

Metastasis is responsible for the high mortality of uveal melanoma patients. Unfortunately, at the time of diagnosis, many patients already harbor microscopic metastases, thus it is urgent to identify early prognostic markers for metastasis (2). MiRNAs are non-coding small RNAs that have different expression profiles in different cancer types and stages. Some miRNAs, such as miR-20a, miR-17a, and miR-106a have been shown to be up-regulated in uveal melanoma, while others, like miR-145 and miR-204, to be downregulated (20). Additionally, miR-34a, let-7b, and miR-199a expression levels have been suggested to be correlated with metastasis of uveal melanoma $(21,22)$. Thus, miRNA expression may represent a highly accurate biomarker for metastatic risk in uveal melanoma. In this study, we identified strongly decreased expression of miR-9 in highly invasive uveal melanoma cells compared with the corresponding poorly invasive cells. These data indicated that some special miRNAs may be developed as a new diagnostic marker for progression and metastasis of uveal melanoma.

Currently, controversy exists regarding the effects of miR-9 on cancer progression. In most cases, miR-9 functions as a tumor suppressor, such as in gastric cancer, colorectal cancer, pancreatic adenocarcinoma, and medulloblastoma (6,7,23-25). In addition, miR-9 expression levels have been shown to be negatively correlated with recurrence in ovarian cancer and clear cell renal cell carcinoma $(26,27)$. However, miR-9 has been reported as an oncogene in endometrial cancer and gastric cancer $(28,29)$. Previous studies also showed miR-9 had opposite roles in cancer metastasis. MiR-9 has been shown to promote metastasis of breast cancer and colorectal cancer by targeting E-cadherin and promoting cell motility $(9,10)$. Recently, Liu et al obtained different results that miR-9 was downexpressed in metastatic melanoma and indirectly upregulated E-cadherin through a NF- $\kappa$ B1-Snail1 pathway, thereby suppressing melanoma proliferation and metastasis (11). Since the lack of lymphatics in the eyes, uveal melanoma has a strong predilection for hematogenous metastasis, thereby rendering uveal melanoma a unique model for studying the hematogenous dissemination of cancer (30). Hence, we shed light on the regulation of miR-9 in hematogenous dissemination. In our study, we showed miR-9 reduced migration and invasion of highly invasive uveal melanoma cells. However, we showed that miR-9 had no significant 
effect on cell proliferation in uveal melanoma. The discrepancies in miR-9 effects might be partly explained with cancer types, stages, cell lines, or even different technical platforms. It is also possible that miR-9 plays different roles in tumor development, progression, metastasis and recurrence.

To date, several miR-9 target genes have been confirmed in different cancer types, such as $\mathrm{NF}-\kappa \mathrm{B} 1$ in gastric cancer, E-cadherin in breast cancer, FOXO1 in endometrial cancer, CDX2 in gastric cancer $(7,9,28,29)$. As we were pursuing to clarify the mechanism of miR-9 on tumor cell migration and invasion, $\mathrm{NF}-\kappa \mathrm{B} 1$ which played vital roles in uveal melanoma development and progression attracted our interests. Gao et al reported that the expression of NF- $\kappa \mathrm{B}$ p105/p50 dramatically increased in melanoma and was correlated with melanoma progression (31). Dror et al detected activation of $\mathrm{NF}-\kappa \mathrm{B} 1$ and $\mathrm{NF}-\kappa \mathrm{B} 2$ pathway in both primary and metastases uveal melanoma (17). Consistent with these reports, we also observed increased NF- $\mathrm{B} 1$ expression in highly invasive cell lines in comparison with the relative poorly invasive cell lines. Furthermore, we also confirmed the post-transcriptional regulation of $\mathrm{NF}-\kappa \mathrm{B} 1$ by miR-9 in uveal melanoma. These findings extend our knowledge of miRNA/ $\mathrm{NF}-\kappa \mathrm{B}$ signaling pathway in uveal melanoma and provide additional evidence for developing $\mathrm{NF}-\kappa \mathrm{B}$ to a therapeutic target.

$\mathrm{NF}-\kappa \mathrm{B} 1$ facilitates invasion and metastasis partly by transcriptional regulation of MMP-2, MMP-9 and VEGFA, which are closely associated with uveal melanoma progression. Vaisanen et al have indicated MMP-2 as an prognostic marker for high metastatic risk in uveal melanoma (14). El-Shabrawi et al have shown that MMP-9 is predominantly expressed in highly aggressive uveal melanoma cells (32). A recent report showed that high level of VEGFA was correlated with the number and location of micrometastases in a murine model of uveal melanoma (33). In this study, we observed that MMP-2, MMP-9, and VEGFA altered in the same pattern as NF- $\kappa$ B1. Thus, NF- $\kappa$ B1-regulated MMP-2, MMP-9, and VEGFA may contribute to miR-9-suppressed metastasis of uveal melanoma.

In conclusion, our results clearly showed that miR-9 was significantly downregulated in the highly invasive uveal melanoma cell lines and could suppress cell migration and invasion. It functioned at least in part through direct targeting $\mathrm{NF}-\kappa \mathrm{B} 1$ expression and downregulation of its downstream genes such as MMP-2, MMP-9, and VEGFA. Thus, the antimetastatic capabilities of miR-9 seem to behave as a critical safeguard against the acquisition of metastatic potential. Therefore, rescuing miR-9 may offer a novel strategy for blocking tumor metastasis.

\section{Acknowledgements}

This study was supported by grants from the National Natural Science Foundation of China (nos. 30873099, 81102458 and 81172004) and the Priority Academic Program Development of Jiangsu Higher Education Institutions (PAPD). We thank Professor Elisabeth A. Seftor for providing the human uveal melanoma cell lines.

\section{References}

1. Seftor EA, Meltzer PS, Kirschmann DA, Pe'er J, Maniotis AJ, Trent JM, Folberg R and Hendrix MJ: Molecular determinants of human uveal melanoma invasion and metastasis. Clin Exp Metastasis 19: 233-246, 2002.

2. Triozzi PL, Eng C and Singh AD: Targeted therapy for uveal melanoma. Cancer Treat Rev 34: 247-258, 2008.

3. Singh AD, Turell ME and Topham AK: Uveal melanoma: trends in incidence, treatment, and survival. Ophthalmology 118: 1881-1885, 2011.

4. Sun Q, Cong R, Yan H, Gu H, Zeng Y, Liu N, Chen J and Wang B: Genistein inhibits growth of human uveal melanoma cells and affects microRNA-27a and target gene expression. Oncol Rep 22: 563-567, 2009.

5. Nicoloso MS, Spizzo R, Shimizu M, Rossi S and Calin GA: MicroRNAs - the micro steering wheel of tumour metastases. Nat Rev Cancer 9: 293-302, 2009.

6. Tsai KW, Liao YL, Wu CW, Hu LY, Li SC, Chan WC, et al: Aberrant hypermethylation of miR-9 genes in gastric cancer. Epigenetics 6: 1189-1197, 2011.

7. Wan HY, Guo LM, Liu T, Liu M, Li X and Tang H: Regulation of the transcription factor NF-kappaB1 by microRNA-9 in human gastric adenocarcinoma. Mol Cancer 9: 16, 2010.

8. Hu X, Schwarz JK, Lewis JS, Huettner PC, Rader JS, Deasy JO, et al: A microRNA expression signature for cervical cancer prognosis, Cancer Res 70: 1441-1448, 2010.

9. Ma L, Young J, Prabhala H, Pan E, Mestdagh P, Muth D, et al: miR-9, a MYC/MYCN-activated microRNA, regulates E-cadherin and cancer metastasis. Nat Cell Biol 12: 247-256, 2010.

10. Zhu L, Chen H, Zhou D, Li D, Bai R, Zheng S and Ge W: MicroRNA-9 up-regulation is involved in colorectal cancer metastasis via promoting cell motility. Med Oncol 29: 1037-1043, 2012.

11. Liu S, Kumar SM, Lu H, Liu A, Yang R, Pushparajan A, Guo W and $\mathrm{Xu} X$ : MicroRNA-9 up-regulates E-cadherin through inhibition of NF-кB1-Snaill pathway in melanoma. J Pathol 226: 61-72, 2012.

12. Amiri KI and Richmond A: Role of nuclear factor-kappa B in melanoma. Cancer Metastasis Rev 24: 301-313, 2005.

13. Pereira SG and Oakley F: Nuclear factor-kappaB1: regulation and function. Int J Biochem Cell Biol 40: 1425-1430, 2008.

14. Vaisanen A, Kallioinen M, von Dickhoff K, Laatikainen L, Hoyhtya $\mathrm{M}$ and Turpeenniemi-Hujanen T: Matrix metalloproteinase-2 (MMP-2) immunoreactive protein - a new prognostic marker in uveal melanoma? J Pathol 188: 56-62, 1999.

15. Sahin A, Kiratli H, Soylemezoglu F, Tezel GG, Bilgic S and Saracbasi O: Expression of vascular endothelial growth factor-A, matrix metalloproteinase-9, and extravascular matrix patterns and their correlations with clinicopathologic parameters in posterior uveal melanomas. Jpn J Ophthalmol 51: 325-331, 2007.

16. Hendrix MJ, Seftor EA, Meltzer PS, Gardner LM, Hess AR, et al: Expression and functional significance of VE-cadherin in aggressive human melanoma cells: role in vasculogenic mimicry. Proc Natl Acad Sci USA 98: 8018-8023, 2001.

17. Dror R, Lederman M, Umezawa K, Barak V,Pe'er J and Chowers I: Characterizing the involvement of the nuclear factor-kappa $\mathrm{B}$ (NF kappa B) transcription factor in uveal melanoma. Invest Ophthalmol Vis Sci 51: 1811-1816, 2010.

18. Yan $C$ and Boyd DD: Regulation of matrix metalloproteinase gene expression. J Cell Physiol 211: 19-26, 2007.

19. Karst AM, Gao K, Nelson CC and Li G: Nuclear factor kappa B subunit $\mathrm{p} 50$ promotes melanoma angiogenesis by upregulating interleukin-6 expression. Int J Cancer 124: 494-501, 2009.

20. Yang $C$ and Wei $W$ : The miRNA expression profile of the uveal melanoma. Sci China Life Sci 54: 351-358, 2011.

21. Yan D, Zhou X, Chen X, Hu DN, Dong XD, Wang J, et al: MicroRNA-34a inhibits uveal melanoma cell proliferation and migration through downregulation of c-Met. Invest Ophthalmol Vis Sci 50: 1559-1565, 2009.

22. Worley LA, Long MD, Onken MD and Harbour JW: MicroRNAs associated with metastasis in uveal melanoma identified by multiplexed microarray profiling. Melanoma Res 18: 184-190, 2008.

23. Bandres E, Agirre X, Bitarte N, Ramirez N, Zarate R, RomanGomez J, et al: Epigenetic regulation of microRNA expression in colorectal cancer. Int J Cancer 125: 2737-2743, 2009. 
24. Omura N, Li CP, Li A, Hong SM, Walter K, Jimeno A, et al: Genome-wide profiling of methylated promoters in pancreatic adenocarcinoma. Cancer Biol Ther 7: 1146-1156, 2008.

25. Ferretti E, De Smaele E, Po A, Di Marcotullio L, Tosi E, Espinola MS, et al: MicroRNA profiling in human medulloblastoma. Int J Cancer 124: 568-577, 2009.

26. Laios A, O'Toole S, Flavin R, Martin C, Kelly L, Ring M, et al: Potential role of miR-9 and miR-223 in recurrent ovarian cancer. Mol Cancer 7: 35, 2008.

27. Hildebrandt MA, Gu J, Lin J, Ye Y, Tan W, Tamboli P, et al: Hsa-miR-9 methylation status is associated with cancer development and metastatic recurrence in patients with clear cell renal cell carcinoma. Oncogene 29: 5724-5728, 2010.

28. Myatt SS, Wang J, Monteiro LJ, Christian M, Ho KK, Fusi L, et al: Definition of microRNAs that repress expression of the tumor suppressor gene FOXO1 in endometrial cancer. Cancer Res 70: 367-377, 2010.
29. Rotkrua P, Akiyama Y, Hashimoto Y, Otsubo T and Yuasa Y: MiR-9 downregulates CDX2 expression in gastric cancer cells. Int J Cancer 129: 2611-2620, 2011.

30. Wöll E, Bedikian A and Legha SS: Uveal melanoma: natural history and treatment options for metastatic disease. Melanoma Res 9: 575-581, 1999.

31. Gao K, Dai DL, Martinka M and Li G: Prognostic significance of nuclear factor-kappaB p105/p50 in human melanoma and its role in cell migration. Cancer Res 66: 8382-8388, 2006.

32. El-Shabrawi Y, Ardjomand N and Radner H: MMP-9 is predominantly expressed in epithelioid and not spindle cell uveal melanoma. J Pathol 194: 201-206, 2001.

33. Crosby MB, Yang H, Gao W, Zhang L and Grossniklaus HE: Serum vascular endothelial growth factor (VEGF) levels correlate with number and location of micrometastases in a murine model of uveal melanoma, Br J Ophthalmol 95: 112-117, 2011. 